\title{
Neural correlates of attentional and mnemonic processing in event-based prospective memory
}

\author{
Justin B. Knight 1,2, Lauren E. Ethridge ${ }^{1,2}$, Richard L. Marsh' ${ }^{1}$ and Brett A. Clementz, ${ }^{1,2 *}$ \\ Department of Psychology, University of Georgia, Athens, GA, USA \\ Biolmaging Research Center, University of Georgia, Athens, GA, USA
}

Edited by:

Stephen A. Engel, University of Minnesota, USA

\section{Reviewed by:}

Robert West, lowa State University, USA

Stephen A. Engel, University of Minnesota, USA

\section{*Correspondence:}

Brett A. Clementz, Psychology

Department, Psychology Building,

University of Georgia, Athens, GA

30602, USA.

e-mail:clementz@uga.edu
Prospective memory (PM), or memory for realizing delayed intentions, was examined with an event-based paradigm while simultaneously measuring neural activity with high-density EEG recordings. Specifically, the neural substrates of monitoring for an event-based cue were examined, as well as those perhaps associated with the cognitive processes supporting detection of cues and fulfillment of intentions. Participants engaged in a baseline lexical decision task (LDT), followed by a LDT with an embedded PM component. Event-based cues were constituted by color and lexicality (red words). Behavioral data provided evidence that monitoring, or preparatory attentional processes, were used to detect cues. Analysis of the event-related potentials (ERP) revealed visual attentional modulations at 140 and 220 ms poststimulus associated with preparatory attentional processes. In addition, ERP components at 220, 350, and 400 ms post-stimulus were enhanced for intention-related items. Our results suggest preparatory attention may operate by selectively modulating processing of features related to a previously formed event-based intention, as well as provide further evidence for the proposal that dissociable component processes support the fulfillment of delayed intentions.

Keywords: prospective memory, preparatory attention, EEG, ERP, cue detection, lexical decision task

\section{INTRODUCTION}

Prospective memory (PM) refers to cognitive processes that enable completion of intentions. People commonly form intentions that cannot be realized at the current moment, but that must be remembered and performed at some time in the future. Examples of such future intentions include remembering to discuss a new research idea with a colleague after class or remembering to take the trash to the road on Monday for pick-up the following day. Only in the last two decades has memory for future intentions become a focus of serious experimental inquiry in cognitive psychology (McDaniel and Einstein, 2007). Less effort has been devoted to advancing our understanding of the neural mechanisms underlying PM. Several neural components (e.g., N300, prospective positivity, and parietal old-new effect) and anatomical regions (e.g., anterior prefrontal cortex, parietal cortex, and anterior cingulate gyrus) have been associated with successful PM (Okuda et al., 1998; West et al., 2000, 2001, 2006; Burgess et al., 2001; West and Krompinger, 2005; Simons et al., 2006; West, 2007, 2008).

The present paper focuses on event-based PM which refers to relying on some environmental cue to elicit a previously established intention (e.g., seeing the colleague in the previous example). To study event-based PM, participants are engaged in an ongoing task (e.g., lexical decision task, pleasantness rating task, or face judgment task) that requires some degree of cognitive processing. Before beginning the ongoing task, people are given an intention that is separate from the ongoing activity (e.g., press a different key when an animal word that begins with the letter " $\mathrm{C}$ " appears in the task). In this case, the $\mathrm{C}$-animal word would be considered an event-based cue. Additionally, lures, items that partially match the cue in some fashion (but do not require a unique response), also can be presented within the ongoing task (e.g., an animal word that does not begin with the letter "C"; Taylor et al., 2004). The inclusion of lures provides an additional avenue for comparison of neural components associated with true prospective cues (West et al., 2003).

The extent to which strategic attentional processes are required for detecting and properly responding to event-based cues are topics of debate in the PM literature. Smith (2003) posits that for an event-based cue to elicit an intention, Preparatory Attentional and Memory processes must be either activated or in a state of readiness (PAM theory; Smith and Bayen, 2004). Alternatively, the multiprocess view (MPV) specifies that successful PM performance can occur without resource demanding attentional processes; that is, event-based cues can sometimes be automatically or spontaneously noticed (e.g., when the ongoing task processing directly overlaps with the processing necessary to notice the cue or the cue is highly salient). In other instances, however, MPV assumes that preparatory attention is necessary (McDaniel and Einstein, 2000; Einstein and $\mathrm{McDaniel}, 2005)$. In both theories, relying on preparatory processes to strategically monitor for a cue is ostensibly resource demanding. The costs are typically exhibited in slower responding to the ongoing task (i.e., task interference) when an intention is activated and the person is monitoring for the intention-related cue. Preparatory attention requires some additional allocation of attention towards the PM component of the task (Marsh et al., 2002b, 2003). Some research has examined the neural correlates of the task interference that results from preparatory attention (Simons et al., 2006; West et al., 2006, 2007; West, 2007), with the lateral anterior prefrontal and parietal cortices appearing to be the main brain regions involved in this process (Simons et al., 2006; Reynolds et al., 2009). 
West and colleagues have reported manifest event-related potentials (ERP) modulations beginning around $200-400 \mathrm{~ms}$ post-stimulus on trials when participants had an active intention and were monitoring for event-based cues relative to trials when participants did not have an intention (West et al., 2006, 2007). When these neural modulations typically begin is unclear because one study found sustained modulations beginning as early as $200 \mathrm{~ms}$ poststimulus (West et al., 2006) while another study did not find ERP effects of preparatory attention until 300-400 ms post-stimulus (West et al., 2007). Further, West et al. (2007) reported a latent variable neural component associated with preparatory attention that onset around $100 \mathrm{~ms}$ post-stimulus. Thus, the stage of processing at which preparatory attentional processing exerts its influence in service of detecting intention-related cues is unclear. In addition, it is currently unknown if preparatory attention can modulate components of early sensory processing associated with ongoing trial stimuli when an intention is active.

The early components of visual evoked potentials occurring between 80 and $200 \mathrm{~ms}$ post-stimulus can be modulated by selective attention to a stimulus location (Hillyard and Anllo-Vento, 1998) and they may be modulated by selective attention to color (Omoto et al., 2007; Schoenfeld et al., 2007). Selective attention has been proposed to emerge from top-down control mechanisms that modulate brain activity to either suppress or enhance sensory representations in accordance with current task goals (Hillyard and Anllo-Vento, 1998). According to this view, frontal and posterior parietal cortices contribute to an attentional control network that can bias sensory processing of stimulus attributes (i.e., spatial and non-spatial features) in order to facilitate information processing (Desimone and Duncan, 1995; Kastner and Ungerleider, 2000). Depending on task demands, these attentional modulations can exert effects at different levels of information processing (Ruz and Nobre, 2008). In regards to word processing, selective attention modulates the N400, which is thought to reflect analysis of semantic characteristics (Kiefer and Brendel, 2006). Recent work (Ruz and Nobre, 2008) also provides evidence that attentional manipulations can affect early orthographic and phonological, in addition to semantic, processing.

In the PM literature, preparatory attentional processes are proposed to function by assessing whether the features of the current stimulus map onto those attributes that constitute an event-based cue (Smith et al., 2007). That is, a retrieval mode is thought to be instantiated and maintained across trials in preparation to treat stimuli as potential cues to retrieve stored intentions (Guynn, 2003; Einstein and McDaniel, 2008). Also, periodic recognition checks are thought to be performed on presented stimuli in service of detecting occurrences of the event-based cue (Guynn, 2003; Smith et al., 2007; Einstein and McDaniel, 2008). In the present experiment, the ongoing task required participants to assess the lexicality of a string of letters that was presented in one of seven colors where words presented in red were the event-based cues which required a unique response during the intention condition. Since physical characteristics of stimuli are thought to be processed prior to language-related processing (e.g., Hauk et al., 2006; Holcomb and Grainger, 2006), preparatory attention may operate to first bias color processing then facilitate linguistic processing of presented items, in order to determine if the current stimulus is related to a previously formed intention. If preparatory attention functions in such a manner, then we would expect to find modulation of neural activity associated with early visual-perceptual processing as well as linguistic processing (i.e., greater for the intention condition compared to the baseline condition). These results would be consistent with preparatory attention selectively modulating early stages of stimulus processing in order to detect the occurrence of event-based cues.

When event-based cues are detected, latencies to respond those cues are typically slowed relative to ongoing task word responses (Marsh et al., 2002b, 2003). Analysis of the slowed responding incurred by detected cues has provided an additional method by which to examine the processes that support prospective remembering. This slowing to cues, termed cue interference, is thought to be a consequence of several cognitive processes that subserve successful fulfillment of intentions in the presence of intentionrelated cues. Marsh et al. (2003) proposed four component processes of successful intention completion: detection, verification, response retrieval, and coordination. Detection refers to the initial recognition of an intention-related cue as being relevant to a previously formed intention. Verification ensures that all of the criteria necessary for eliciting a prospective response are met (e.g., lures that partially match the cue on some feature would be rejected). Response retrieval supports retrieval of the to-be-performed action from memory. Finally, to fulfill the intention the intended response must be coordinated with the response required by the ongoing task. These component processes have been proposed to subserve completion of intentions when an intention-related cue is encountered.

Marsh et al. (2003) gave participants an intention to make a special response when they encountered any of four related words (i.e., words from the category of animals) or any of four unrelated words. When participants detected those cues, the slowed responding incurred by unrelated cues was greater than the slowing to related cues, ostensibly due to the increased demands on detecting and verifying that each of the unrelated words was in fact a cue and required a prospective response. Additionally, lures which have partial feature overlap with cues have been shown to elicit slowing relative to ongoing trial words, indicative of detecting those stimuli as intention-related and needing to verify that they do not meet all the criteria of a cue (Taylor et al., 2004). When the type of cue is held constant and the intended response is to say the target word that was previously studied with the cue, latency to respond to the cue is greater when the target word is unassociated than when the target word is associated to the cue. Slowing in this case is thought to emanate from the increased demands on the response retrieval process (Marsh et al., 2003). These findings, among others (Loft and Yeo, 2007), lend evidence for the potentially dissociable contributions that these processes support in the fulfillment of intentions. Particularly relevant to the present experiment are the detection and verification processes because cues as well as lures were embedded in the current paradigm. The extent to which these processes are supported by distinct neural modulations is not clearly understood.

Three neural components have been associated with the successful fulfillment of prospective intentions: the N300, prospective positivity, and parietal old-new effect (West et al., 2000, 2001, 2006; West 
and Krompinger, 2005; West, 2007). The N300 response is greater for prospective hits (i.e., cues that were correctly responded to) than for ongoing trial stimuli and missed prospective cues (West and Ross-Munroe, 2002; West and Krompinger, 2005). Such differences suggest a specific role of the N300 in cue detection. Additionally, enhanced activity over the central, parietal, and occipital areas has been observed in ERP studies of PM (West et al., 2001; West and Wymbs, 2004; West, 2007). This modulation, referred to as prospective positivity, can onset as early as $400 \mathrm{~ms}$ post-stimulus and may persist until 1000 ms post-stimulus (West and Krompinger, 2005). West and Krompinger (2005) broadly proposed that a combination of retrieval and post-retrieval processes, such as coordination of the intended response with the response required by the ongoing task, are supported by the prospective positivity. In addition, the parietal old-new effect, typically occurring between 500 and $800 \mathrm{~ms}$ post-stimulus (Vilberg and Rugg, 2009), is thought to function in support of the retrospective memory component of PM (e.g., retrieval of the intended action once a cue has been detected; West and Krompinger, 2005). To date, it is unknown whether the verification processing is supported by a distinct neural mechanism, or whether this processing may be encompassed in neural modulations associated with cue detection or the retrospective memory component (i.e., N300 or parietal old-new effect).

Brain activity associated with the actual presentation of the cue has received the most focus in ERP research on event-based PM. Neural modulations occurring across ongoing trials that support prospective remembering have only recently become a focus of study (e.g., Simons et al., 2006; West et al., 2006; West, 2007; Reynolds et al., 2009). According to the PAM theory, an active engagement in preparatory attentional processes is always necessary for a prospective intention to be fulfilled (Smith, 2003; Smith and Bayen, 2004). Thus, in addition to examining the neural correlates associated with the presentation of the cue, the exploration of the neural underpinnings that support such preparatory attentional processes warrants further scrutiny. In the present experiment, participants completed a baseline lexical decision task (LDT) in addition to a LDT with an incorporated PM intention. Our goal was to examine the effects of monitoring for an event-based cue defined by color and lexicality (red words) on the early stages of visual sensory processing and to elucidate the neural mechanisms that support the first two component processes that are thought to subserve fulfillment of event-based intentions when intentionrelated items are encountered, cue detection and verification.

\section{MATERIALS AND METHODS PARTICIPANTS}

Participants were 12 students (three males and nine females; mean age $=22.7$ years, $\mathrm{SD}=4.7$ ) recruited from The University of Georgia student population. Seven subjects received course credit and five received monetary compensation $(\$ 10)$ for their participation. This project was approved by the UGA Institutional Review Board, and all subjects provided informed consent prior to participation.

\section{STIMULI}

A total of 900 stimuli, half of which were words and the other half pronounceable nonwords were used in the present study. Word stimuli ranged from 3 to 10 letters in length, had a syllable count of 1-4, and had a medium or high frequency of occurrence, as specified in the Kucera and Francis (1967) norms. Nonword stimuli were all pronounceable, and matched for average number of syllables with word stimuli. Some stimuli had been used in a previous publication (Marsh et al., 2000). Nonwords were created by altering one to three letters in a medium or highly frequent word (e.g. flour became plour). Stimuli were presented in one of seven colors (e.g. yellow, green, red, blue, white, brown, or silver) with no difference in luminance levels between colors (luminance was $5 \mathrm{~cd} / \mathrm{m}^{2}$ against a $0.5 \mathrm{~cd} / \mathrm{m}^{2}$ background). Stimuli were presented on a $21^{\prime}$ flat screen color monitor in Times New Roman font, and the largest letter was $1^{\prime}$ in height. The monitor was placed $100 \mathrm{~cm}$ from the participant's eyes.

\section{EEG RECORDING}

The EEG data were recorded vertex-referenced using a 256-sensor Geodesic Sensor Net and NetAmps 200 amplifiers (Electrical Geodesics; EGI, Eugene, OR, USA). The sensor net was adjusted until all pedestals were properly seated on the scalp (i.e., not sitting on thick mats of hair that could result in bridging between sensors, e.g., Greischar et al., 2004). Individual sensor impedances were adjusted until they were below $50 \mathrm{k} \Omega$ (Ferree et al., 2001). In addition, an electrolyte bridge test was conducted between all pairs of sensors prior to recording (Tenke and Kayser, 2001), and, if there was evidence of bridging, sensors were adjusted until bridging was no longer evident (this was rarely required). Data were sampled at $250 \mathrm{~Hz}$ with an analog filter bandpass of $0.1-200 \mathrm{~Hz}$. A Macintosh G4 running EGI's Netstation software was used for data collection, E-Prime (PST Net, Pittsburgh, PA, USA) running on a $\mathrm{PC}$ was used for stimulus presentation, and two four-button response pads (one for each hand) were used to collect finger press responses to stimulus events.

\section{PROCEDURE}

Participants were told that they would be participating in a study during which their brain waves would be recorded while they saw words and nonwords on the monitor. To gain an assessment of the impact of adding a PM task to the ongoing task, a baseline LDT session was completed first. During the LDT-only session, 200 items (half words, half nonwords) were presented. There was no mention of a PM task until after participants had completed the baseline LDT-only session. Participants were simply told to respond by pressing predefined buttons with the same finger on both hands to indicate the occurrence of words (index finger of both the left and right hands) versus nonwords (middle finger of both the left and right hands).

Following the LDT-only task, there was a brief break during which PM instructions were given. Participants were reminded of the finger press instructions for words and nonwords, and in addition were told that if they saw a red word they should press down all four buttons simultaneously (again, using the index and middle finger on each hand). The red items comprised $20 \%$ of the 700 trials presented during this part of the experiment. Half of these red items were words (cues) and half were nonwords (lures). The following abbreviations will be used as short-hand for the six conditions of interest: baseline LDT-items (LDT-words; LDT-nonwords), nonred items presented when the 
PM intention was active (PM-words, PM-nonwords), and red items presented when the PM intention was active (PM-cues, PM-lures).

\section{EEG data analysis}

Sensors around the neck and cheeks were excluded from analysis, leaving 211 sensors. Data were then pre-processed following recommendations (with minimal modification) made by Junghofer et al. (2000). Raw data were visually inspected offline for bad sensor recordings. Bad sensors were interpolated (no more than $5 \%$ of sensors for any subject) using a spherical spline interpolation method as implemented in BESA 5.1 (MEGIS Software, Gräfelfing, Germany). Data were transformed to an average reference and digitally filtered from 1 to $30 \mathrm{~Hz}(6 \mathrm{db} /$ octave rolloff, zero-phase). Artifact correction was achieved by using the Independent Component Analysis (ICA) toolbox in EEGLAB 4.515 (Delorme and Makeig, 2004) running under Matlab (Version 7.0, MathWorks, Natick, MA, USA). ICA allows artifact removal without spatially distorting the data by using higher-order statistics to produce temporally independent signals in the data (Onton et al., 2006). Independent components with topographies representing saccades, blinks, and heart rate artifact were removed according to published guidelines (Jung et al., 2000). Grand averages for correct responses to items in each condition were created and baseline-adjusted using the $250 \mathrm{~ms}$ pre-stimulus interval.

\section{Statistical analyses of voltage data}

Data analyses were performed using programs written in Matlab. First, to identify ERP peaks that were above baseline noise level, grand averaged plots were derived for each condition. Due to interference of motor-related activations occurring after $600 \mathrm{~ms}$ resulting from button presses (i.e., responses began occurring around this time point for some participants), we focused our analysis on the cortical activations occurring in the first $600 \mathrm{~ms}$ epoch following each stimulus presentation. There were identifiable, above-baseline, peaks for each condition around 140, 220, 400, and 520 ms post-stimulus (see Figures 1-4). An additional peak was present only for the PM condition at $350 \mathrm{~ms}$ poststimulus. The latencies of these peaks did not differ significantly as a function of condition. The latencies of peaks in the grand averaged data were used as guidelines for determining the individual peak time points; scalp potentials were averaged within $20 \mathrm{~ms}$ time windows centered on the latency of each peak. A set of planned contrasts at each ERP peak were used to evaluate the main hypotheses: (i) to test for word/nonword differences, LDTwords were compared to LDT-nonwords and PM-words were compared to PM-nonwords, (ii) to test for monitoring (preparatory attention) effects, PM-words were compared to LDT-words and PM-nonwords were compared to LDT-nonwords, and (iii) to test for cue-specific effects, PM-cues were compared to PMlures, PM-cues were compared to (PM-words + LDT-words)/2, and PM-lures were compared to (PM-nonwords + LDT-nonwords)/2. [Due to the low percentage of cues that were missed $(M=12 \%)$, a sufficiently stable average could not be obtained for missed prospective cues, thus a comparison of detected cues to missed cues could not be conducted.]
Because multi-sensor EEG data result in significant activations of multiple sensors that are in close spatial proximity, a cluster threshold technique (see Gilmore et al., 2005, 2009; Krusemark et al., 2008, for examples) was used to control for possible increases in Type I error as a result of performing multiple comparisons (e.g., Forman et al., 1995). Traditional Bonferroni correction is inappropriately conservative with brain activity data, so alternative methods have been developed to manage the multiple comparison problem (e.g., Worsley, 2003; Kilner et al., 2005). One such method, cluster thresholding (e.g., Forman et al., 1995), integrates the probability of significance for an individual source or sensor location with that for a cluster of such locations. Cluster thresholding is done because real brain activations are likely to result in correlated changes in clusters of sources and/or sensors. The following statistical significance rules were determined based on the noise level of the data (estimated from the prestimulus baseline) and Monte Carlo simulations calculated using AlphaSim (Cox, 1996). To maintain the familywise alpha lower than 0.025 within a comparison, the following conditions needed to be met: (1) an individual test at a single time point for a given sensor was significant at $p<0.04$; (2) at least five other neighboring sensors were statistically significant at $p<0.04$. For clusters of sensors in which there were significant effects, voltages were averaged over those sensors to characterize the directionality of those differences.

In addition, when there were significant effects, the similarities in between-conditions spatial distributions of that ERP component were determined by calculating Pearson correlations using the sensors as observations and either $t$-values or voltage as the dependent variable (see, e.g., Wang et al., 2009). Comparisons of $t$-values over sensors were used when related comparisons (e.g., LDT-words versus LDT-nonwords and PM-words versus PM-nonwords) both showed significant sensor clusters. A high correlation $(>0.90)$ between $t$-maps indicates that both comparisons were accounted for by similar sensor clusters. A high correlation $(>0.90)$ between voltage distributions suggests that similar neural sources were accounting for stimulus processing across conditions.

\section{RESULTS}

\section{BEHAVIORAL DATA}

The set of planned contrasts described above were used to analyze the correct response rates and reaction times for all conditions and trial types. For the percentage correct variable, the difference between words and nonwords did not approach significance in the LDT condition (LDT-words $M=97.9 \%, \mathrm{SE}=0.6, \mathrm{LDT}$-nonwords $M=96.9 \%, \mathrm{SE}=1.2), t(11)=-0.8, p=0.441$, or in the PM condition (PM-words $M=93.3 \%, \mathrm{SE}=2.3$, PM-nonwords $M=91.9 \%$, $\mathrm{SE}=1.5), t(11)=-0.740, p=0.475$. There was a numerical difference in correct response rates for LDT-words and PM-words, although the difference failed to reach conventional levels of significance, $t(11)=-2.061, p=0.064$. The PM-nonwords had significantly fewer correct identifications than did the LDT-nonwords, $t(11)=-2.69, p=0.021$. The difference between percent correct for cues $(M=88.2 \%, \mathrm{SE}=2.1)$ and lures $(M=83.6 \%, \mathrm{SE}=4.1)$ was not significant, $t(11)=0.832, p=0.423$. However, lures were correctly identified significantly less than all other nonwords 
$(\mathrm{LDT}+\mathrm{PM}$ nonwords $/ 2 M=94.4 \%, \mathrm{SE}=0.9), t(11)=-2.944$, $p=0.013$, as were cues than all other words (LDT $+\mathrm{PM}$ words $/ 2$ $M=95.6 \%, \mathrm{SE}=1.3), t(11)=-2.41, p=0.035$.

For reaction times, participants were significantly faster at identifying LDT-words $(M=780.6 \mathrm{~ms}, \mathrm{SE}=40.8)$ than LDTnonwords $(M=922.7 \mathrm{~ms}, \mathrm{SE}=46.7), t(11)=3.28, p=0.009$; however, response times did not differ significantly between PM-words $(M=849.9 \mathrm{~ms}, \quad \mathrm{SE}=31.7)$ and PM-nonwords $(M=881.3 \mathrm{~ms}, \mathrm{SE}=36.9), t(11)=1.613, p=0.135$. Latencies to identify words was significantly faster for the LDT condition than the PM condition, $t(11)=4.059, p=0.002$, but the difference in nonword latencies between conditions did not approach significance, $t(11)=-1.502, p=0.161$. This slowing to respond to PMwords reveals a clear task interference effect once the participants were given a prospective intention. Response latencies to cues $(M=907.0 \mathrm{~ms}, \mathrm{SE}=35.2)$ and lures $(M=934.2 \mathrm{~ms}, \mathrm{SE}=34.5)$ did not differ significantly, $t(11)=-1.093, p=0.298$. However, lures were responded to significantly more slowly than all other nonwords (LDT + PM nonwords $/ 2 M=902 \mathrm{ms,} \mathrm{SE=39.7),}$ $t(11)=-2.828, p=0.016$. In addition, participants responded significantly slower to cues than all other words (LDT + PM words/2 $M=815.3 \mathrm{~ms}, \mathrm{SE}=35.5), t(11)=4.402, p=0.001$, indicating a cue interference effect.

\section{ELECTROPHYSIOLOGICAL DATA}

The ERP results are presented by time of peak activity (140, 220, 400 , and $520 \mathrm{~ms}$ post-stimulus) onset for all comparisons with the addition of a peak at $350 \mathrm{~ms}$ for the red PM-items. Statistical significance was determined using the cluster thresholding procedure described in the section "Materials and Methods." Plots of $t$-values and voltage distributions over the head surface are provided for significant effects.

\section{Word versus nonword effects}

There were no significant differences between words and nonwords at the $140 \mathrm{~ms}$ peak. At the 220 and $400 \mathrm{~ms}$ ERP peaks, PM-words and PM-nonwords significantly differed (see Figure 1); however, LDT-words and LDT-nonwords did not significantly differ at these time points. At $220 \mathrm{~ms}$, although their topographic distributions were remarkably similar ( $r=0.99$ for the between-conditions voltage distributions over all 211 sensors), PM-nonwords had stronger activity than PM-words over the occipital region (Mean cluster difference $=-0.13 \mu \mathrm{V}, \mathrm{SE}=0.04), t(11)=-3.23, p=0.008$, (see Figure 1). At $400 \mathrm{~ms}$, the voltage distributions between PMwords and PM-nonwords were notably different ( $r=0.48$ for the between-conditions voltage distributions over all 211 sensors) with the voltage peak being more parietal for PM-words and more centro-medial for PM-nonwords (see Figure 1). Indeed, PM-words had stronger activity than PM-nonwords for a posterior sensor cluster ( $\mathrm{M}$ posterior cluster diff $=0.25 \mu \mathrm{V}, \mathrm{SE}=0.06$ ), $t(11)=3.96, p=0.002$, and PM-nonwords had stronger activity than PM-words for a frontal sensor cluster ( $M$ frontal cluster diff $=-0.29 \mu \mathrm{V}, \mathrm{SE}=0.08), t(11)=-3.6, p=0.004$, (see Figure 1). Finally, at $520 \mathrm{~ms}$, both PM-words and LDT-words significantly differed from their nonword counterparts in highly similar fashion (see Figure $1 ; r=0.91$ for the between-conditions $t$-value distributions over all 211 sensors). Once again, words had a voltage peak that was more parietal ( $\mathrm{M}$ posterior cluster diff $=-0.28 \mu \mathrm{V}$, $\mathrm{SE}=0.06), t(11)=-4.84, p=0.01$, and nonwords had a voltage peak that was more centro-medial $(\mathrm{M}$ frontal cluster diff $=0.31 \mu \mathrm{V}$, $\mathrm{SE}=0.07), t(11)=4.74, p=0.001$.

\section{Monitoring (attention) effects}

There were significant effects at 140 and $220 \mathrm{~ms}$ for both PM-word versus LDT-word and PM-nonword versus LDT-nonword comparisons, with the statistical pattern of those effects being highly similar for both word/nonword comparisons (see Figure 2; $r=0.92$ for the between-conditions $t$-value distributions over all 211 sensors at $140 \mathrm{~ms} ; r=0.95$ for the between-conditions $t$-value distributions over all 211 sensors at $220 \mathrm{~ms}$ ). At $140 \mathrm{~ms}$, although their topographic distributions were remarkably similar $(r=0.99$ for the between-conditions voltage distributions over all 211 sensors), nonred PM-items (both words and nonwords) had stronger activity than LDT-items (words and nonwords) over occipital regions (M cluster diff $=0.24 \mu \mathrm{V}, \mathrm{SE}=0.07), t(11)=3.29, p=0.007$, (see Figure 2). Likewise, at $220 \mathrm{~ms}$, despite highly similar topographic distributions ( $r=0.99$ for the between-conditions voltage distributions over all 211 sensors), nonred PM-items (both words and nonwords) had stronger activity than LDT-items (words and nonwords) over both occipital (M posterior cluster diff $=-0.38 \mu \mathrm{V}$, $\mathrm{SE}=0.09), t(11)=-4.35, p=0.001$, and centro-frontal regions $(\mathrm{M}$ frontal cluster diff $=0.29 \mu \mathrm{V}, \mathrm{SE}=0.07), t(11)=4.24, p=0.001$, (see Figure 2). Finally, there were significant differences between the PM-nonword and LDT-nonword conditions at the $400 \mathrm{~ms}$ ERP peak (see Figure 2). Despite highly similar topographic distributions ( $r=0.92$ for the between-conditions voltage distributions over all 211 sensors), and contrary to the effects at 140 and 220 ms, LDT-nonwords had stronger activity than PM-nonwords over a slightly right centro-parietal region (M cluster diff $=0.18 \mu \mathrm{V}$, $\mathrm{SE}=0.04), t(11)=4.36, p=0.001$, (see Figure 2$)$.

\section{Cue-specific effects}

At 140 ms, neither the PM-cues versus (PM-words + LDT-words/2) nor the PM-lures versus (PM-nonwords + LDT-nonwords/2) comparisons differed significantly. At $220 \mathrm{~ms}$, however, both of these comparisons revealed significant sensor clusters (see Figure 3). The pattern of these significant relationships were highly similar between the two comparisons ( $r=0.92$ for the between-conditions $t$-value distributions over all 211 sensors), indicating that red items, regardless of their status (cue, lure), were processed differently than nonred items at this time point. In addition, the topographic distributions of voltages were highly similar between red and nonred items for the $220 \mathrm{~ms}$ ERP peak ( $r=0.97$ for the between-conditions voltage distributions over all 211 sensors), but red items (both PMcues and PM-lures) had significantly higher voltages over occipitalparietal regions than did nonred items (M cluster diff $=-0.39 \mu \mathrm{V}$, $\mathrm{SE}=0.11), t(11)=-3.43, p=0.006$, (see Figure 3 ). An additional indication that red items were processed differently from non-red items was the ERP peak at $350 \mathrm{~ms}$ that was present for only PMcues and PM-lures (see Figure 4). There were no significant differences, however, between cues and lures at this peak, and the spatial distribution of their neural activations were highly similar ( $r=0.96$ for the between-conditions voltage distributions over all 211 sensors). 


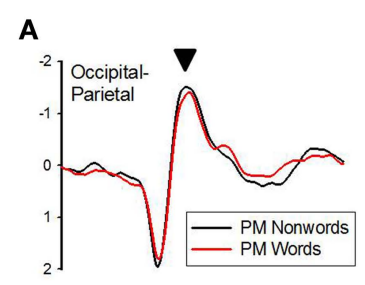

B
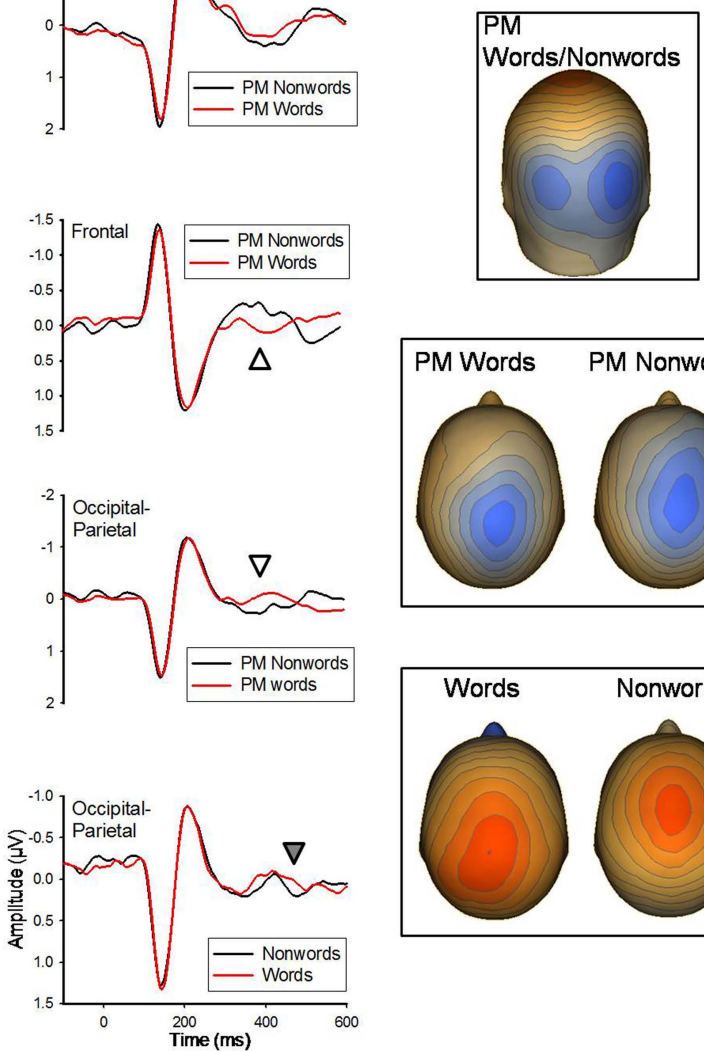

FIGURE 1 | (A) Grand-averaged ERP waveforms for PM-words and PMnonwords for the $220 \mathrm{~ms}$ (marked with black arrow) and $400 \mathrm{~ms}$ (white arrow) components, and for LDT/PM-words and LDT/PM-nonwords for the $520 \mathrm{~ms}$ (gray arrow) component. ERP waveforms were derived by averaging sensors from significant clusters that resulted from the respective planned contrasts. Negative is plotted up. (B) Topographical voltage distributions averaged within time windows centered on the peak latency of each component for which there were significant effects. Positive isopotential lines are in red, negative isopotential lines are in blue. Isopotential line scales are: $0.82 \mu \mathrm{V} / \mathrm{step}$ for $220 \mathrm{~ms}, 0.25 \mu \mathrm{V} / \mathrm{step}$ for $400 \mathrm{~ms}$, and $0.28 \mu \mathrm{V} / \mathrm{step}$ for $520 \mathrm{~ms}$ components. Due to similarities in topographies PM-words and PM-nonwords are averaged together and presented on one topography for the $220 \mathrm{~ms}$ component. PM-words and PM-nonwords are presented separately for the 400 ms effect, and due to similarities in differences across conditions at 520 ms, PM- and LDT-words are averaged together and compared with the average of PM- and LDT-nonwords. (C) Plots of $t$-values (absolute value taken) over the head surface indicate the sensor clusters for which there were significant effects between PM-words versus PM-nonwords at peaks 220 and 400 ms post-stimulus, and between all words and nonwords at 520 ms post-stimulus. The LDT-words versus LDT-nonwords and PM-words versus PM-nonwords effects are presented together due to the high similarity between the two comparisons at 520 ms post-stimulus. The critical $t$-value $(t=2.3281)$ is marked on the scale.
At $400 \mathrm{~ms}$, both the PM-cues versus (PM-words + LDTwords/2) and the PM-lures versus (PM-nonwords + LDT-nonwords/2) comparisons showed significant regions of difference (see Figure 4). The pattern of these significant relationships were only modestly similar ( $r=0.73$ for the between-conditions $t$-value distributions over all 211 sensors), so these effects are presented separately for the PM-cue and PM-lure comparisons. In addition, the topographic distributions of voltages were only modestly correlated between PM-cues and the other word items ( $r=0.51$ for the between-conditions voltage distributions over all 211 sensors) and PM-lures and the other nonword items ( $r=0.62$ for the betweenconditions voltage distributions over all 211 sensors), suggesting different neural source configurations for red versus nonred stimuli. For the PM-cues comparison, cues had stronger activity over a left tempo-parietal sensor cluster than did the other word items $(\mathrm{M}$ cluster diff $=0.29 \mu \mathrm{V}, \mathrm{SE}=0.06), t(11)=4.48, p=0.001$; this same pattern was also apparent for the lures versus other nonwords comparison (M cluster diff $=0.24 \mu \mathrm{V}, \mathrm{SE}=0.06$ ), $t(11)=3.8$, $p=0.003$, (see Figure 4). Finally, at $520 \mathrm{~ms}$, there was a significant difference between PM-cues and other word items (see Figure 4). In addition, the topographic distributions of voltages were only modestly correlated between PM-cues and the other word items ( $r=0.71$ for the between-conditions voltage distributions over all 211 sensors), again suggesting different neural source configurations for these two item classes. PM-cues had significantly less extreme voltage in a centro-parietal sensor cluster than did other word items $(\mathrm{M}$ cluster diff $=-0.30 \mu \mathrm{V}, \mathrm{SE}=0.11), t(11)=-2.77$, $p=0.02$, (see Figure 4). 
A

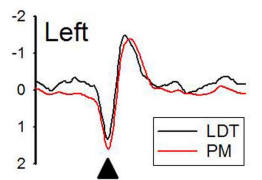

$\boldsymbol{\Delta}$

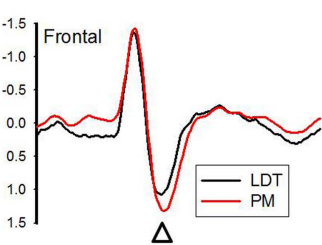

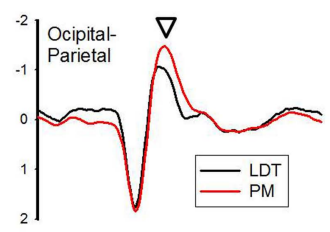

Time (ms)
B
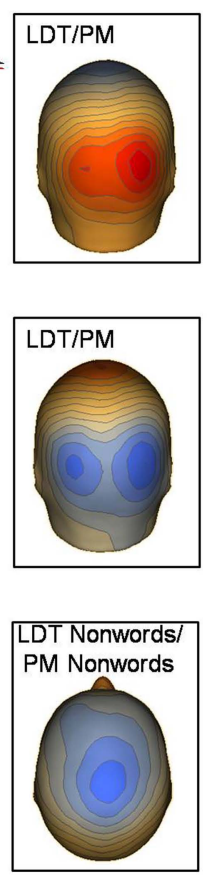

C
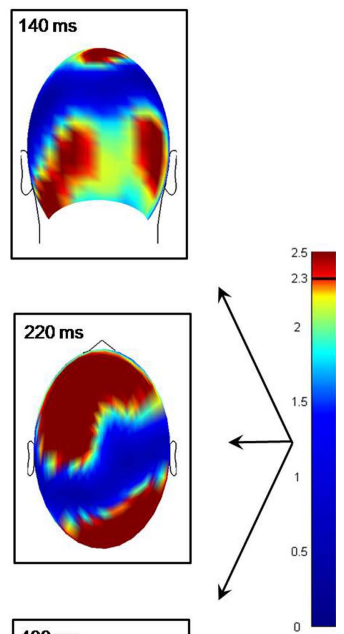

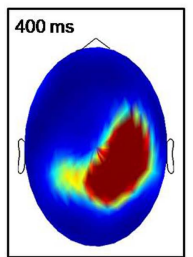

negative isopotential lines are in blue. Isopotential line scales are: $0.9 \mu \mathrm{V} /$ step for $140 \mathrm{~ms}, 0.67 \mu \mathrm{V} / \mathrm{step}$ for $220 \mathrm{~ms}$, and $0.32 \mu \mathrm{V} / \mathrm{step}$ for $400 \mathrm{~ms}$ components. Due to similarities in topographies between conditions, LDT-items and PM-items are averaged and presented on one voltage topography for the 140 and 220 ms effects, and LDT-nonwords and PM-nonwords are averaged and presented on one voltage topography for the $400 \mathrm{~ms}$ effect. (C) Plots of $t$-values (absolute value taken) over the head surface indicate the sensor clusters for which there were significant effects between LDT-items and PM-items at peaks 140 and 220 ms post-stimulus, and between LDT-nonwords and PM-nonwords at $400 \mathrm{~ms}$ post-stimulus. The critical $t$-value $(t=2.3281)$ is marked on the scale.

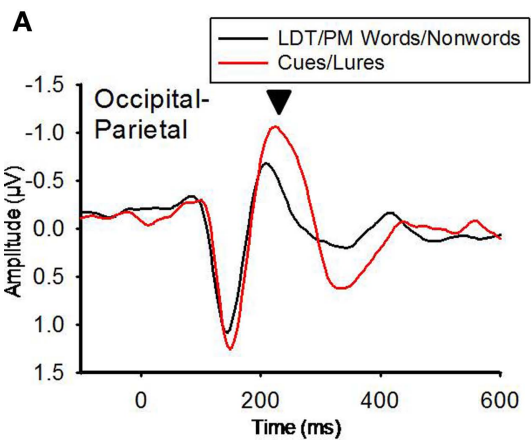

FIGURE 3 | (A) Grand-averaged ERP waveforms for LDT/PM words/nonwords and Cues/Lures for the 220 ms component (marked with black arrow). Occipital-parietal ERP waveforms were derived by averaging sensors from the significant cluster that resulted from the planned contrast. Negative is plotted up. (B) A topographical voltage distribution averaged within time windows centered on the peak latency of the $220 \mathrm{~ms}$ component. Positive isopotential lines are in red, negative isopotential lines are in blue. Isopotential line scale is: $0.64 \mu \mathrm{V} / \mathrm{step}$. Due to similarities in topographic distributions across
B

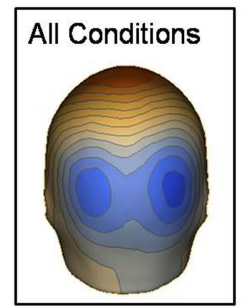

C

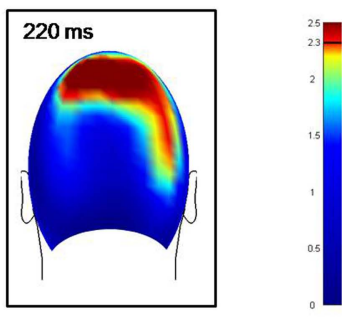

conditions, they are averaged and presented as one voltage topography. (C) A plot of $t$-values (absolute value taken) over the head surface indicates the sensor clusters for which there were significant effects between LDT/ PM-words versus cues and LDT/PM-nonwords versus lures at $220 \mathrm{~ms}$ post-stimulus. The two effects are presented together due to the high similarity between the two comparisons, suggesting red PM-items were preferentially processed at this time point. The critical $t$-value $(t=2.3281)$ is marked on the scale. 


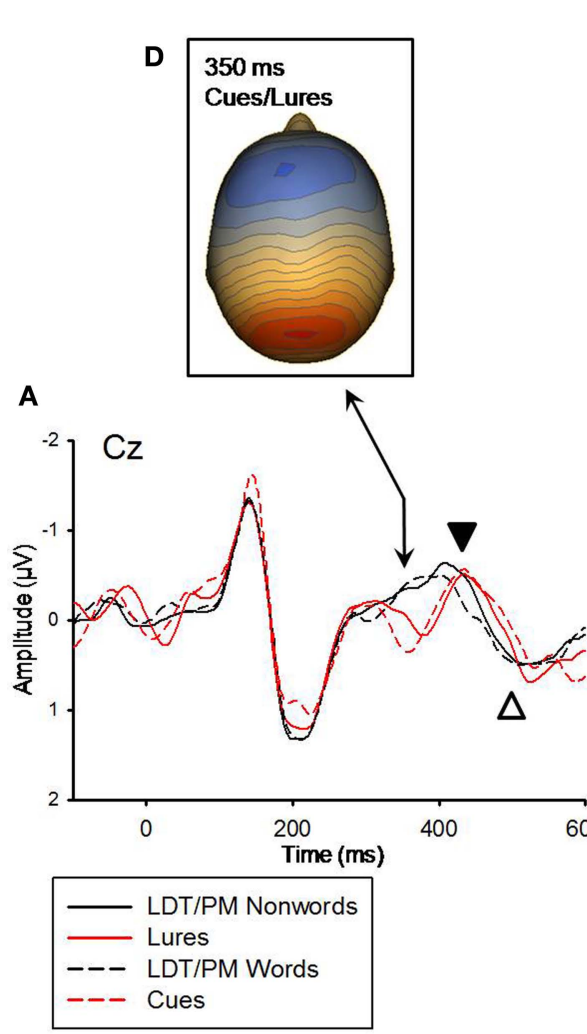

B
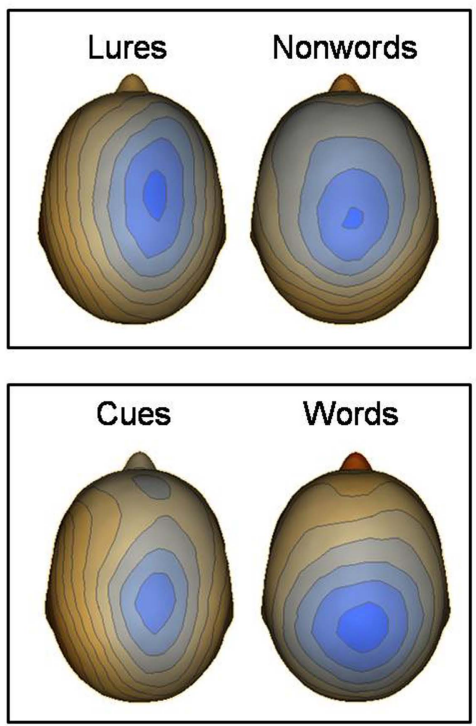

600

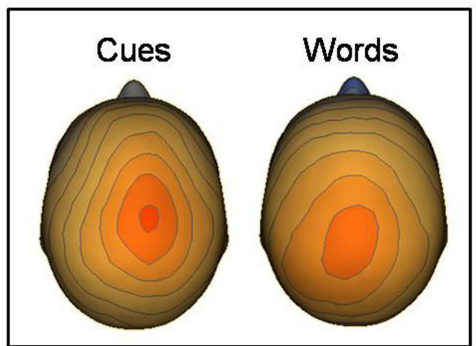

C
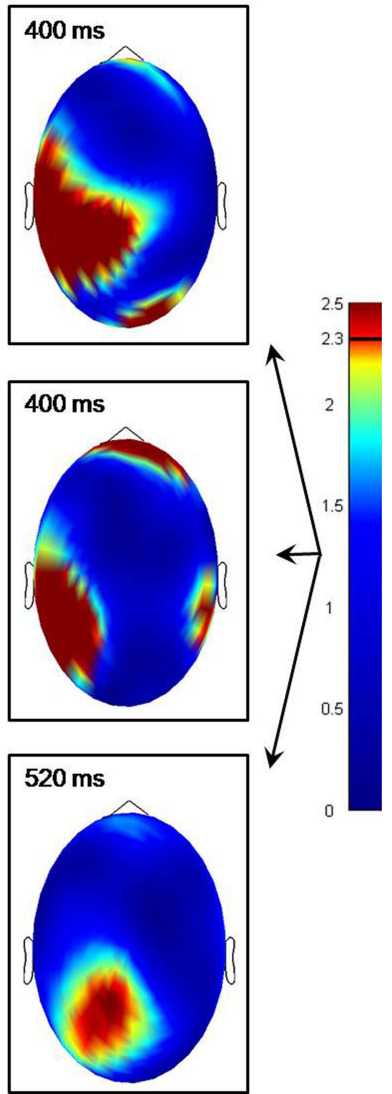

FIGURE 4 | (A) Grand-averaged ERP waveforms for LDT/PM-nonwords, lures, LDT/PM-words, and cues for the $350 \mathrm{~ms}, 400 \mathrm{~ms}$ (marked with black arrow), and $520 \mathrm{~ms}$ (white arrow) components. ERP waveforms were derived from electrode $\mathrm{C} z$ which best represented each component. Negative is plotted up. (B) Topographical voltage distributions averaged within time windows centered on the peak latency of each component for which there were significant effects. Positive isopotential lines are in red, negative isopotential lines are in blue. Isopotential line scales are: $0.32 \mu \mathrm{V} /$ step for $400 \mathrm{~ms}$ and $0.29 \mu \mathrm{V} / \mathrm{step}$ for $520 \mathrm{~ms}$ ERPs. Due to differences in between condition $t$-value distributions, lures versus LDT/PM-nonwords and cues versus LDT/PM-words are presented separately for the $400 \mathrm{~ms}$ effect. At $520 \mathrm{~ms}$ post-stimulus, these comparisons only revealed a significant effect for cues versus LDT/PM-words. (C) Plots of $t$ values (absolute value taken) over the head surface indicate the sensor clusters for which there were significant effects in comparisons of lures versus LDT/PMnonwords and cues versus LDT/PM-words for the 400 and $520 \mathrm{~ms}$ components. The critical $t$-value $(t=2.3281)$ is marked on the scale. (D)

Topographical voltage distribution averaged within a time window centered on the $350 \mathrm{~ms}$ peak. Isopotential line scale is: $0.31 \mu \mathrm{V} / \mathrm{step}$. Due to similarities in topographic distributions, Cues and lures are averaged and presented as one topography for the $350 \mathrm{~ms}$ ERP that was only elicited by intention-related items.

\section{DISCUSSION}

In the present experiment, we sought to elucidate the effects of preparatory attention on early visual-perceptual processing as well as examine the neural underpinnings supporting both the detection and the verification processes that subserve fulfillment of eventbased intentions. Our results revealed several ERP components that appear to support such attentional and mnemonic processing. Moreover, these components appear to be specifically related to the engagement of preparatory attention, detection of intention-related items, and verification of the appropriateness of the intentionrelated items in our task. ERP effects of lexical processing will be addressed first, followed by a discussion of the behavioral and ERP results related to PM processes.

Regarding the lexicality effects, we found vast differences across conditions in the extent to which neural modulations associated with words and nonwords differed. Neural modulations of words and nonwords did not differ until around $500 \mathrm{~ms}$ post-stimulus in the LDT condition which is more consistent with proposals that lexical processing occurs between 300 and $500 \mathrm{~ms}$ post-stimulus (McKinnon et al., 2003; Carreiras et al., 2005; Braun et al., 2006). In the PM condition, however, nonwords elicited increased neural activity over the occipital region around $220 \mathrm{~ms}$ post-stimulus which is more consistent with proposals that lexical access can occur early in the processing stream (Sereno et al., 1998; Hauk et al., 2006). Processing of lexical properties, therefore, appeared to be affected by embedding a PM intention related to lexical characteristics.

In the PM condition, around $400 \mathrm{~ms}$ post-stimulus, nonwords elicited a neural modulation that was stronger over centro-medial sensors, whereas words produced a stronger modulation over parietal sensors. These modulations likely represent the N400, associated with semantic analysis, and follow previous findings on the effects of nonwords on the N400 (Braun et al., 2006; Hauk et al., 2006). In addition, our analysis revealed an effect of lexicality in the $\mathrm{PM}$ condition around $500 \mathrm{~ms}$ post-stimulus with increased neural 
activity over the parietal region for words and increased activity over the frontal region for nonwords, which may reflect formation of semantic associations for the words and further decision making to reject the nonwords as nonlexical (Hauk et al., 2006).

Pertaining to results associated with PM processes, the behavioral measures provided clear evidence for the task interference and cue interference effects. Task interference was evident in the increased reaction times to nonred words in the PM-condition as compared with words in the baseline LDT. This slowed responding provides evidence that in the PM-condition participants were allocating some level of attention toward the PM component of the task set (Marsh and Hicks, 1998). Thus, preparatory attentional processes were relied upon to successfully fulfill the intention in the present study. The presence of task interference is consistent with both PAM theory and the MPV, as well as with recent findings showing that preparatory attention was used to detect a color cue (Reynolds et al., 2009; see also Smith et al., 2007). Additionally, we found significantly increased response times to cues as compared with all other words. Slowing to cues has been termed cue interference (Marsh et al., 2003), and reflects the additional cognitive processing which may be necessary to detect an event-based cue and successfully fulfill the intention associated with it. The finding that lures were responded to more slowly and less accurately (i.e., in terms of false alarming, or responding as if they were cues) than other nonwords is consistent with previous research (West and Craik, 1999; Bisiacchi et al., 2009), suggesting lures are recognized as intention-related and require some level of processing to verify they are not a cue.

The behavioral results support the notion that preparatory attentional processes were relied upon to detect event-based cues in the PM-condition. Preparatory attentional processes are thought of as supporting a state of readiness to detect and respond to intention-related items (Smith, 2003; Smith and Bayen, 2004; Smith et al., 2007). These processes operate during the interval in which the intention can be executed (i.e., in the PM-condition) and are engaged across ongoing trials in preparation for the opportunity to execute the intended action. According to Guynn (2003, 2008), preparatory attention is comprised of instantiating a prospective retrieval mode, which is a preparedness to treat incoming stimuli as potential cues for retrieving a stored intention, and periodic item checking to determine if the incoming stimuli match the attributes of the event-based cue. These attentional processes have been proposed to function by mapping the features of the presented item onto those that constitute an event-based cue (Smith et al., 2007). Under this conceptualization of preparatory attention, the processes are dynamic and dependent upon the current intention. That is, preparatory attention may function like an attentional set that is constrained by the features of the currently active intention.

In feature-based selective attention tasks it has been proposed that when one has knowledge in advance about the attributes that constitute a target then a goal-directed attentional set is formed which serves to facilitate processing of target-defining features (Corbetta and Shulman, 2002). In studies of feature-based selective attention, comparisons of attended versus unattended stimuli have generally revealed an enhanced negativity for attended items over the occipital-parietal region that is maximal between 140 and $300 \mathrm{~ms}$ post-stimulus, termed the "selection negativity" (SN; Harter and Aine, 1984; Hillyard and Anllo-Vento, 1998). Also, a positive modulation over the frontal region maximal over roughly the same time range as the $\mathrm{SN}$ has been found to be enhanced for attended stimuli in feature-based selective attention tasks, termed the "selection positivity" (SP; Anllo-Vento et al., 1998; Hillyard and AnlloVento, 1998). These modulations have been proposed to reflect enhanced feature processing as a result of allocation of attention and have been found in selective attention for a variety of features including color, shape, and orientation (Harter and Aine, 1984; Hillyard and Anllo-Vento, 1998; Kopp et al., 2007). Additionally, some studies of selective attention to color have reported an earlier enhanced posterior positivity around 110-200 ms post-stimulus for attended versus unattended stimuli (Anllo-Vento et al., 1998; Lange et al., 1998; Schoenfeld et al., 2007). Importantly for the current purposes, these attentional modulations have been shown to be evident across the more frequent ongoing nontarget trials (AnlloVento et al., 1998; Schoenfeld, 2007).

With regard to the neural correlates associated with preparatory attention in the current experiment, an enhanced neural modulation of early visual perceptual processing at $140 \mathrm{~ms}$ post-stimulus over the occipital-parietal region was found for nonred PM-items relative to baseline LDT-items (Figure 2). This component was characterized by an increased positivity for nonred PM-items and is similar in latency and topography to the early posterior positivity reported in the aforementioned studies of selective attention to color (Anllo-Vento et al., 1998; Lange et al., 1998; Schoenfeld et al., 2007). In addition, an enhanced negativity over the occipital region and an enhanced positivity over the centro-frontal region, both of which were maximal around $220 \mathrm{~ms}$ post-stimulus, were found for nonred PM-items relative to LDT-items (Figure 2). The differences across conditions in these two components likely reflect neural modulations similar to the $\mathrm{SN}$ and SP, respectively (Harter and Aine, 1984; Hillyard and Anllo-Vento, 1998). Thus, these attentional modulations for the PM-condition relative to the LDT-condition demonstrate evidence that preparatory attentional processes facilitated early color processing of incoming stimuli in a manner consistent with an attentional set constrained by a cuedefining feature. These findings provide, to our knowledge, the first evidence that effects of preparatory attention can be found on modulations of manifest ERP components supporting early visual processing. This facilitation could possibly support item checking (Guynn, 2003) to determine if the color of the current item matches that which constitutes a cue. This notion gains further support considering that the intention-related red items (i.e., cues and lures) elicited a more extreme voltage at 220 and $350 \mathrm{~ms}$ post-stimulus relative to the nonred items, reflecting an allocation of attention to the intention-related feature red. Furthermore, an earlier onset of lexicality effects was also evident in the PM-condition compared to the LDT-condition. A recent study demonstrated that the levels of word processing can be influenced by the attentional demands of the task (Ruz and Nobre, 2008). Here, the engagement of preparatory attention to detect cues defined in part by lexicality appears to have facilitated word processing in the PM-condition. This earlier neural dissociation of words and nonwords in the PMcondition provides additional evidence that preparatory attention, similar to a goal-directed attentional set, facilitated processing of cue-defining attributes. Interestingly, by $400 \mathrm{~ms}$ post-stimulus 
LDT-items were found to have a more extreme voltage than nonred PM-items, possibly suggesting the linguistic processing occurring at that time-point in the LDT-condition had already occurred in the PM-condition. Thus, preparatory attention may function from the outset of visual processing to selectively modulate processing of stimulus features (i.e., perceptual and lexical here) related to the intention, in the service of detecting cues. The similarity between the attentional modulations observed in visual attention tasks and those reported here in a PM task suggest examining a combination or comparison of these tasks in future work could elucidate the extent to which the neural mechanisms of preparatory attentional processes and selective attention processes are shared or distinct.

Our results lend support to the notion that item level processing can support preparatory attention (Guynn, 2003; Smith et al., 2007). In a recent event-related fMRI study of PM, Reynolds et al. (2009) found no transient stimulus locked increases in neural activity when participants were relying on preparatory attentional processes to detect intention-related cues. Instead, their findings revealed increases in sustained activity, particularly in the anterior prefrontal cortex, across the PM task which they interpreted as supporting processes associated with preparatory attention. Thus, item level monitoring did not appear to be relied upon in their study. A couple of key differences exist between their paradigm and ours which may account for the discrepancy in results. The cue in their task was constituted by a single feature (i.e., when a specified color appeared during an $\mathrm{N}$-back task participants were to make a special key press), whereas a cue in the presented study was constituted by two features (i.e., color and lexicality). Thus, this increase in the criteria that must be met for an item to be considered a cue may have resulted in higher demands on preparatory attention in the current paradigm. Moreover, lures, items that have partial feature overlap with cues, were embedded in our task and were not present in the study by Reynolds et al. (2009). The presence of lures could have influenced participants to rely more heavily on preparatory attention in order to ensure that they successfully detected cues and rejected lures (Smith and Bayen, 2004). These paradigm differences may explain why item level monitoring was found here and not in their study. Nevertheless, the present findings provide further evidence that item level processing functions in support of preparatory attention in some circumstances (West et al., 2007).

A potential point of concern regarding the current paradigm (i.e., LDT-condition always preceded the PM-condition) warrants consideration. One may propose that differences between the PMcondition relative to the LDT-condition are driven by practice with the LDT or fatigue effects from completing the PM-condition last. Considering the behavioral results should help allay concerns about this potential limitation. Latencies to respond to words in the PM-condition were significantly increased relative to LDT-words whereas PM-nonword latencies did not reliably differ from LDT-nonword latencies. In fact, the numerical difference between PM- and LDT-nonword latencies was actually in the opposite direction than that of PM- and LDT-words. Thus, the behavioral results showed no clear practice (i.e., general speeded responding) or fatigue (i.e., general slowed responding) effects. Moreover, the ERP results did not reveal consistent enhancements or attenuations across components for the PM- versus LDT-condition comparisons that might be expected if the observed differ- ences were solely driven by task order. We, nevertheless, cannot unambiguously rule out the possibility that task order may have had some effect. However, our rationale for using this design emanates from findings that effects of preparatory attention (i.e., slowed ongoing task responding) are in some cases still present even after an intention has become irrelevant (Marsh et al., 2006; West, 2007). Thus, we chose this design to ensure that our baseline LDT-condition was not affected by preparatory attentional processes that may be slow to dissipate after completion of the PMcondition. Similar designs have been successfully implemented in previous studies investigating PM (Smith and Bayen, 2004, 2006; Brewer et al., in press).

Further analyses of the ERP results revealed an increased negativity over the occipital-parietal region at $220 \mathrm{~ms}$ for intention-related red PM-items relative to all other LDT/PM stimuli (Figure 3). This component is similar in latency and topography to the N300 associated with cue detection (West et al., 2001) which has been statistically dissociated from the $\mathrm{N} 2$ and $\mathrm{N} 2 \mathrm{pc}$ components related to processing of targets or physically deviant stimuli (West et al., 2001; West and Wymbs, 2004). Similarity in this neural component between cues and color matched lures (i.e., red nonwords) may result from the additional language processing necessary to reject the nonword letter strings as nonlexical (Braun et al., 2006). However, our data additionally revealed a difference in lexical processing in the $\mathrm{PM}$-condition at $220 \mathrm{~ms}$ (Figure 1). The $220 \mathrm{~ms}$ component, therefore, may support parallel processing of stimulus features (i.e., color and lexicality) associated with the previously formed intention. Thus, it appears that this modulation supports detection of intention-related items.

Nonetheless, cues and lures do not appear to be completely dissociated at this point, as they similarly produced an ERP at $350 \mathrm{~ms}$ that was not present for any other trial type, indicating an effect specifically supporting processing of intention-related material (see Figure 4). This peak resembles the P3 which is thought to reflect allocation of attentional resources to target processing of perceptually deviant stimuli and context updating of the stimuli with a mental representation in working memory (Polich, 2007; Gilmore et al., 2009). Though modulations similar to this component have been observed in studies of PM (West et al., 2006), the functional significance it may serve in the realization of delayed intentions is not fully understood. The $350 \mathrm{~ms}$ component may reflect the initiation of the verification process in which a stimulus detected as similar to an intention-related cue is further assessed as to whether its features exactly match the features of the cue (i.e., a process that would ostensibly rely on attentional and mnemonic processing).

Cues and lures continued to differ from their word and nonword counterparts at $400 \mathrm{~ms}$ over the left tempo-parietal region, reflecting an additional component likely supporting PM processing (e.g., completion of the verification process, or rejection of lures). Subsequent to this component, our data revealed a modulation at $520 \mathrm{~ms}$ post-stimulus that differentiated cues from other words but not lures from other nonwords. At this time-point, cues elicited a less extreme positive voltage over the parietal region relative to words. This less extreme voltage for cues may reflect a task-set reconfiguration (Bisiacchi et al., 2009) which is involved in task switching (Crone et al., 2006). That is, upon detection and verification of a cue participants must switch attention away from the production rules associated with the LDT (i.e., suppress the 
normal word response) and direct attention toward completing the $\mathrm{PM}$ response (i.e., retrieving and executing the intended action; Bisiacchi et al., 2009). Thus, this $520 \mathrm{~ms}$ component may support a suppression of the ongoing task response when a cue is detected and verified as appropriate for requiring a prospective response.

In addition to the component associated with cue detection, our analysis revealed two ERP components (i.e., ERP peaks 350 and 400) that were modulated by intention-related items. The prospective positivity, broadly proposed to support retrieval and post-retrieval processes in the realization of delayed intentions (West and Krompinger, 2005), does not seem to account for these modulations. The P3, which may have been reflected in the modulation of intention-related items at $350 \mathrm{~ms}$ post-stimulus, has been statistically dissociated from the prospective positivity (West and Wymbs, 2004; West et al., 2006). However, the functional significance the $\mathrm{P} 3$ may support in prospective remembering is unclear. Additionally, both ERP effects at 350 and $400 \mathrm{~ms}$ post-stimulus were characterized by distinctly different voltage distributions than the prospective positivity, yet both were modulated for intention-related items. These findings suggest that in future studies these components warrant a closer examination as to the role they may support in the fulfillment of delayed intentions.

The differences between these effects and those found previously by West and colleagues may be attributable to the ongoing task used (i.e., the LDT). To our knowledge, this is the first prospective memory ERP study to use the LDT. Making lexical decisions involves orthographic, phonological, and semantic processing that serve to assess the lexicality of the presented stimulus (Hauk et al., 2006). Indeed, this processing would not directly map onto the processing involved in tasks that have been used previously (e.g., N-back and category judgment). Considering that the demands of the ongoing task have been shown to affect PM performance (Marsh et al., 2002a), the type of ongoing task used in the current paradigm may well have contributed to the differences in the ERP effects presented here and those found previously. Nevertheless, the LDT is commonly used in behavioral examination of the cognitive processes that support PM (Marsh et al., 2003; Smith,

\section{REFERENCES}

Anllo-Vento, L., Luck, S. J., and Hillyard, S. A. (1998). Spatio-temporal dynamics of attention to color: evidence from human electrophysiology. Hum. Brain Mapp. 6, 216-238.

Bisiacchi, P. S., Schiff, S., Ciccola, A., and Kliegel,M. (2009). The role of dual-task and task-switch in prospective memory: behavioural data and neural correlates. Neuropschologia 47, 1362-1373.

Braun, M., Jacobs, A. M., Hahne, A., Ricker, B., Hofmann, M., and Hutzler, F. (2006). Model-generated lexical activity predicts graded ERP amplitudes in lexical decision. Brain Res. 1073-1074, 431-439.

Brewer, G. A., Knight, J. B., Unsworth, N., and Marsh, R. L. (in press). Individual differences in event-based prospective memory: evidence for multiple processes supporting cue detection. Mem. Cognit.
Burgess, P. W., Quayle, A., and Frith, C. D. (2001). Brain regions involved in prospective memory as determined by positron emission tomography. Neuropsychologia 39, 545-555.

Carreiras, M., Vergara, M., and Barber, H. (2005). Early event-related potential effects of syllabic processing during visual word recognition. J. Cogn. Neurosci. 17, 1803-1817.

Corbetta, M., and Shulman, G. L. (2002). Control of goal-directed and stimulusdriven attention in the brain. Nat. Rev. Neurosci. 3, 201-215.

Cox, R. W. (1996). AFNI: software for analysis and visualization of functional magnetic resonance neuroimages. Comput. Biomed. Res. 29, 162-173.

Crone, E. A., Wendelken, C., Donohue, S. E., and Bunge, S. A. (2006). Neural evidence for dissociable components 475-486. of task-switching. Cereb. Cortex 16,

2003; Loft and Yeo, 2007; Smith et al., 2007; Brewer et al., in press). Therefore, gaining a further understanding of the neural mechanisms that support prospective remembering in this task and how they may differ across tasks would be informative to behavioral investigation.

Consistent with PAM theory and the MPV, we found that in order to detect cues constituted by two features (i.e., color and lexicality) participants allocated preparatory attention to map stimulus features onto the intention (Smith et al., 2007). There were early neural modulations of visual and lexical processing which may be a manifestation of an intention-constrained attentional set. This idea intimately links forming an attentional set and allocating preparatory attentional processes, and possibly provides a neural marker of such constrained attentional processing. Establishing a neural marker of preparatory attention would provide an avenue by which to test if cue detection (i.e., marked by the N300) could occur in the absence of such preparatory attentional modulations, the results of which would disambiguate two prominent theories of prospective memory (i.e., PAM theory and MPV).

In conclusion, we found modulations of early visual perceptual processing associated with preparatory attentional processes that may support a type of initial stimulus evaluation constrained to attributes of the intention. Further, the cognitive processing (e.g., verification) occurring in addition to cue detection and intention retrieval warrants more focus in the examination of the neural mechanisms supporting PM. We present a potential neural correlate of such processing which may indicate that cue verification is supported by a distinct neural signature. Future work is needed to assess the generalizability of these findings when different intentions and ongoing tasks are implemented.

\section{ACKNOWLEDGMENT}

This research was supported by the John and Mary Franklin Foundation through a fellowship to Justin B. Knight. We thank Gene Brewer for his valuable comments on a previous version of this manuscript.

Delorme, A., and Makeig, S. (2004). EEGLAB: an open source toolbox for analysis of single-trial EEG dynamics including independent component analysis. J. Neurosci. Methods 134 9-21.

Desimone, R., and Duncan, J. (1995). Neural mechanisms of selective visual attention. Annu. Rev. Neurosci. 18, 193-222.

Einstein, G. O., and McDaniel, M. A. (2005). Prospective memory: multiple retrieval processes. Curr. Dir. Psychol. Sci., 14, 286-290.

Einstein, G.O., and McDaniel,M.A. (2008). Prospectivememoryand metamemory: the skilled use of basic attentional and memory processes. In The Psychology of Learning and Motivation, Vol. 48, A S. Benjamin and B. Ross eds (San Diego, CA, Elsevier), pp. 145-173.

Ferree, T. C., Luu, P., Russell, G. S., and Tucker, D. M. (2001). Scalp electrode impedance, infection risk, and EEG data quality. Clin. Neurophysiol. 112, 536-544.

Forman, S. D., Cohen, J. D., Fitzgerald, M., Eddy, W. F., Mintun, M. A., and Noll, D. C. (1995). Improved assessment of significant activation in functional magnetic resonance imaging (fMRI): use of a cluster-size threshold. Magn. Reson. Med. 33, 636-647.

Gilmore, C. S., Clementz, B. A., and Buckley, P.F.(2005).Stimulus sequence affects schizophrenia-normal differences in event processing during an auditory oddball task. Cogn. Brain Res. 24, 215-227.

Gilmore, C.S., Clementz, B. A., and Berg, P. (2009). Hemispheric differences in auditory oddball responses during monaural versus binaural stimulation. Int. J. Psychophysiol. 73, 326-333.

Greischar,L.L., Burghy, C.A., van Reekum, C. M., Jackson, D. C., Pizzagalli, D. A., 
Mueller, C., and Davidson, R.J.(2004). Effects of electrode density and electrolyte spreading in dense array electroencephalographic recording. Clin. Neurophysiol. 115, 710-720.

Guynn,M.J. (2003).A two-process model of strategic monitoring in event-based prospective memory: activation/ retrieval mode and checking. Int. J. Psychol. 38, 245-256.

Guynn,M.J.(2008).Theory of monitoring in prospective memory: Instantiating a retrieval mode and periodic target checking. In Prospective memory: Cognitive neuroscience, developmental, and applied perspectives, $\mathrm{M}$. Kliegel, M. A. McDaniel and G. O. Einstein, eds (New York, Lawrence Erlbaum), pp. 53-76.

Harter, M. R., and Aine, C. (1984). Brain mechanisms of visual selective attention. In: Varieties of attention, R. Parasuraman and D. R. Davies, eds (New York, Academic Press), pp. 293-321.

Hauk, O., Davis, M. H., Ford, M., Pulvermuller, F., and Marslen-Wilson, W.D. (2006). The time course of visual word recognition as revealed by linear regression analysis of ERP data. Neuroimage 30, 1383-1400.

Hillyard, S.A., and Anllo-Vento, L. (1998). Event-related brain potentials in the study of visual selective attention. Proc. Natl. Acad. Sci. U.S.A. 95, 781-787.

Holcomb, P. J., and Grainger, J. (2006). On the time course of visual word recognition: an event-related potential investigation using masked repetition priming. J. Cogn. Neurosci. 18, 1631-1643.

Jung, T. P., Makeig, S., Humphries, C., Lee, T. W., McKeown, M. J., Iragui, V., and Sejnowski, T.J. (2000). Removing electroencephalographic artifacts by blind source separation. Psychophysiology 37, 163-178.

Junghofer, M., Elbert, T., Tucker, D. M., and Rockstroh, B. (2000). Statistical control of artifacts in dense array EEG/MEG studies. Psychophysiology $37,523-532$.

Kastner, S., and Ungerleider, L. G. (2000). Mechanisms of visual attention in the human cortex. Annu. Rev. Neurosci. 23, 315-341.

Kiefer, M., and Brendel, D. (2006). Attentional modulation of unconscious "automatic" processes: evidence from event-related potentials in a masked priming paradigm. J. Cogn. Neurosci. 18, 184-198.

Kilner, J. M., Kiebel, S. J., and Friston, K. J. (2005). Applications of random field theory to electrophysiology. Neurosci. Lett. 374, 174-178.

Kopp, B., Tabeling, S., Moschner, C., and Wessel, K. (2007). Temporal dynamics of selective attention and conflict resolution during cross-dimensional gonogo decisions. BMC Neurosci. 8, doi: 10.1186/1471-2202-8-68

Krusemark, E. A., Keith Campbell, W., and Clementz, B. A. (2008). Attributions, deception, and event related potentials: an investigation of the self-serving bias. Psychophysiology 45, 511-515.

Kucera, H., and Francis, W. N. (1967) Computational Analysis of Present Day American English. Providence, Brown UP.

Lange, J. J., Wijers, A. A., Mulder, L. J., and Mulder, G. (1998). Color selection and location selection in ERPs: differences, similarities and 'neural specificity'. Biol. Psychol. 48, 153-182.

Loft, S., and Yeo, G. (2007). An investigation into the resource requirements of event-based prospective memory. Mem. Cognit. 35, 263-274.

Marsh, R. L., Hancock, T. W., and Hicks, J. L. (2002a). The demands of an ongoing activity influence the success of event-based prospective memory. Psychon. Bull. Rev. 9, 604-610.

Marsh, R. L., Hicks, J. L., and Watson, V. (2002b). The dynamics of intention retrieval and coordination of action in event-based prospective memory. J. Exp. Psychol. Learn. Mem. Cogn. 28 652-659.

Marsh, R. L., and Hicks, J. L. (1998). Event-based prospective memory and executive control of working memory. J. Exp. Psychol. Learn. Mem. Cogn. 24, 336-349.

Marsh, R. L., Hicks, J. L., and Cook, G. I. (2006). Task interference from prospective memories covaries with contextual associations of fulfilling them. Mem. Cognit. 34, 1037-1045.

Marsh, R. L., Hicks, J. L., Cook, G. I., Hansen, J. S., and Pallos, A. L. (2003). Interference to ongoing activities covaries with the characteristics of an event-based intention. J. Exp. Psychol. Learn Mem. Cogn. 29, 861-870.

Marsh, R. L., Hicks, J. L., and Hancock, T. W. (2000). On the interaction of ongoing cognitive activity and the nature of an event-based intention. Appl. Cogn. Psychol. 14, S29-S42.

McDaniel, M. A., and Einstein, G. O. (2000). Strategic and automatic processes in prospective memory retrieval: a multiprocess framework. Appl. Cogn. Psychol. 14, S127-S144.

McDaniel, M. A., and Einstein, G. O. (2007). Prospective Memory: An Overview and Synthesis of an Emerging Field. Thousand Oaks, CA, Sage Publications.

McKinnon, R., Allen, M., and Osterhout, L. (2003). Morphological decomposition involving non-productive mor- phemes: ERP evidence. Neuroreport 14, 883-886.

Okuda, J., Fujii, T., Yamadori, A. Kawashima, R., Tsukiura, T., Fukatsu, R., Suzuki, K., Ito, M., and Fukuda, H. (1998). Participation of the prefrontal cortices in prospective memory: evidence from a PET study in humans. Neurosci. Lett. 253, 127-130.

Omoto, S., Kuroiwa, Y., Wang, C., Li, M., Mizuki, N., and Hakii, Y. (2007). The effect of attended color on the $\mathrm{P} 1 / \mathrm{N} 1$ component of visual eventrelated potentials. Neurosci. Lett. 429, 22-27.

Onton, J., Westerfield, M., Townsend J., and Makeig, S. (2006). Imaging human EEG dynamics using independent component analysis. Neurosci. Biobehav. Rev. 30, 808-822.

Polich, J. (2007). Updating P300: an integrative theory of $\mathrm{P} 3 \mathrm{a}$ and $\mathrm{P} 3 \mathrm{~b}$. Clin. Neurophysiol. 118, 2128-2148.

Reynolds, J. R., West, R., and Braver, T. (2009). Distinct neural circuits support transient and sustained processes in prospective memory and working memory. Cereb. Cortex 19 1208-1221.

Ruz, M., and Nobre, A. C. (2008) Attention modulates initial stages of visual word processing. J. Cogn. Neurosci. 20, 1727-1736.

Schoenfeld, M. A., Hopf, J. M., Martinez, A., Mai, H. M., Sattler, C., Gasde, A., and Heinze, H. J.Hillyard, S.A. (2007) Spatio-temporal analysis of featurebased attention. Cereb. Cortex, 17, 2468-2477.

Sereno, S. C., Rayner, K., and Posner, M. I. (1998). Establishing a time-line of word recognition: evidence from eye movements and event-related potentials. Neuroreport 9, 2195-2200.

Simons, J. S., Scholvinck, M. L., Gilbert, S. J., Frith, C. D., and Burgess, P. W. (2006). Differential components of prospective memory? Evidence from fMRI. Neuropsychologia 44, 1388-1397.

Smith, R. E. (2003). The cost of remembering to remember in event-based prospective memory: investigating the capacity demands of delayed intention performance. J. Exp. Psychol. Learn. Mem. Cogn. 29, 347-361.

Smith, R. E., and Bayen, U. J. (2004). A multinomial model of event-based prospective memory. J. Exp. Psychol. Learn. Mem. Cogn. 30, 756-777.

Smith, R. E., and Bayen, U. J. (2006). The source of adult age differences event-based prospective memory: a multinomial modeling approach. $J$ Exp. Psychol. Learn. Mem. Cogn. 32, 623-635.

Smith, R.E.,Hunt, R. R., McVay, J.C., and McConnel, M. D. (2007). The cost of event-based prospective memory: salient target events. J. Exp. Psychol. Learn. Mem. Cogn. 33, 734-746.

Taylor, R. S., Marsh, R. L., Hicks, J. L., and Hancock, T. W. (2004). The influence of partial-match cues on event-based prospective memory. Memory 12 , 203-213.

Tenke, C. E., and Kayser, J. (2001). A convenient method for detecting electrolyte bridges in multichannel electroencephalogram and eventrelated potential recordings. Clin. Neurophysiol. 112, 545-550.

Vilberg, K. L., and Rugg, M. D. (2009). Functional significance of retrievalrelated activity in lateral parietal cortex: evidence from fmri and erps. Hum. Brain Mapp. 30, 1490-1501.

Wang, J., Brown, R., and Dobkins, K. R., McDowell, J. E., and Clementz, B.A. (2009). Diminished parietal cortex activity accounts for poor motion direction discrimination performance in schizophrenia. Cereb. Cortex.

West, R. (2007). The influence of strategic monitoring on the neural correlates of prospective memory. Mem. Cognit. 35 , 1034-1046.

West, R. (2008). The cognitive neuroscience of prospective memory. In Prospective memory: Cognitive, neuroscience, developmental, and applied perspectives, M. Kliegel, M A. McDaniel and G. O. Einstein, eds (New York, Lawrence Erlbaum), pp. 261-282.

West, R., Bowry, R., and Krompinger, J. (2006). The effects of working memory demands on the neural correlates of prospective memory. Neuropsychologia 44, 197-207.

West, R., and Craik, F. I. (1999). Agerelated decline in prospective memory: the roles of cue accessibility and cue sensitivity. Psychol. Aging 14, 264-272.

West, R., Herndon, R. W., and Crewdson, S. J. (2001). Neural activity associated with the realization of a delayed intention. Brain Res. Cogn. Brain Res. 12 , 1-9.

West, R., Herndon, R. W., and RossMunroe, K. (2000). Event-related neural activity associated with prospective remembering. Appl. Cogn. Psychol. 14, S115-S126.

West, R., and Krompinger,J. (2005). Neural correlates of prospective and retrospective memory. Neuropsychologia $43,418-433$.

West, R., McNerney, M. W., and Travers, S. (2007). Gone but not forgotten: the effects of cancelled intentions on the neural correlates of prospective memory. Int. J. Psychophysiol. 64 215-225. 
West, R., and Ross-Munroe, K. (2002). Neural correlates of the formation and realization of delayed intentions. Cogn. Affect. Behav. Neurosci. 2, 162-173.

West, R., and Wymbs, N. (2004). Is detecting prospective cues the same as selecting targets? An ERP study. Cogn. Affect. Behav. Neurosci. 4, 354-363.

West, R., Wymbs, N., Jakubek, K., and Herndon, R. W. (2003). Effects of intention load and background context on prospective remembering: an event-related brain potential study. Psychophysiology 40, 260-276.

Worsley, K. J. (2003). Detecting activation in fMRI data. Stat. Methods Med. Res. 12, 401-418.

Conflict of Interest Statement: The authors declare that the current research was conducted in the absence of any commercial or financial relationship that could be construed as a potential conflict of interest.

Received: 20 August 2009; paper pending published: 18 November 2009; accepted: 15 January 2010; published online: 09 February 2010.

Citation: Knight JB, Ethridge LE, Marsh $R L$ and Clementz BA (2010) Neural correlates of attentional and mnemonic processing in event-based prospective memory. Front. Hum. Neurosci. 4:5. doi: 10.3389/neuro.09.005.2010

Copyright (c) 2010 Knight, Ethridge, Marsh and Clementz. This is an open-access article subject to an exclusive license agreement between the authors and the Frontiers Research Foundation, which permits unrestricted use, distribution, and reproduction in any medium, provided the original authors and source are credited. 